\title{
MÉTODO E ATO FILOSÓFICO EM HEGEL
}

\author{
Marcos Fábio Alexandre Nicolau ${ }^{1}$
}

\section{Resumo:}

Eis a tarefa, aparentemente irrecusável à filosofia, de buscar a união entre ser e pensar em um sistema que seja capaz de se autofundar e justificar, doando bases sólidas não somente a si, mas a toda e qualquer ciência, o que o faz ser considerado como uma verdadeira doutrina da ciência, capaz de estabelecer os pressupostos básicos a todo e qualquer saber que se queira dizer válido. Sendo em Hegel tal feito realizável tão somente em bases de um método dialético, fruto da própria natureza de começo que traz imanente a si o elemento da contradição, da negação determinada, capaz de promover $o$ autodesenvolvimento de um saber dito absoluto. A dialética hegeliana não é, de forma nenhuma, diferente de seu conteúdo, pois ela é o conteúdo em si mesmo, a estrutura e o desenvolvimento do próprio ser.

Palavras-chave: Método Hegeliano, Tradição Dialética, Contradição.

\begin{abstract}
:
That is the task, apparently irrefutably the philosophy, to seek the union between being and thinking of a system that is capable of self-grounded and justified, donating solid basis not only to itself but to any science, which does be regarded as a genuine doctrine of science, able to establish the basic assumptions to any knowing that you want to say valid. As in Hegel made this feasible only on bases of a dialectical method, the fruit of the very nature of starting that brings you the inherent element of contradiction, denial determined, capable to promote self-development of a knowledge absolute said. The Hegelian dialectic is not, in any way, other than its content, because it is the content itself, the structure and development of the own being.
\end{abstract}

Keywords: Hegelian Method, Dialectic Tradition, Contradiction.

Qual a relação entre filosofia e método? Sabemos que para muitos pensadores a maneira de pensar e de conhecer constitui o próprio objeto da investigação, e caracteriza o conteúdo teórico do que se pretende estudar. O problema do método está dentre um dos mais debatidos na história da filosofia, chegando ao ponto de se estabelecer, dentro da própria filosofia, o assumir explícito de certos pensadores por um método específico,

\footnotetext{
${ }^{1}$ Professor Assistente do Curso de Filosofia da Universidade Estadual Vale do Acaraú - UVA. Doutor em Educação do Programa de Pós-Graduação em Educação Brasileira FACED/UFC. Pesquisador do Grupo de Pesquisas em Filosofia da Religião (GEPHIR/CNPq).
} 
em função do detrimento de qualquer outro, o que é bem delineado por Stein quando afirma que:

a questão do método em Filosofia domina em grande proporção as discussões no campo filosófico, quer para dividi-lo em duas facções, quer para dar a uma delas, não apenas a hegemonia, mas a razão sobre a outra. E não resta dúvida, no momento atual está com nítida vantagem o grupo daqueles pensadores que persegue um trabalho metódico na filosofia e exige um controle crítico dos resultados. (STEIN, 1983, p. 259)

Perspectiva que já fora assumida por G. W. F. Hegel, que não esconde suas pretensões quanto ao método dialético assumido em seu idealismo absoluto:

\begin{abstract}
Isto é já evidente por si mesmo, porque este método não é nada distinto de seu objeto e conteúdo, pois é o conteúdo em si, a dialética que o conteúdo encerra em si mesmo, que o impulsiona para adiante. Claro está que nenhuma exposição poderia considerar-se científica, se não seguir o curso deste método, e se não se adaptar a seu ritmo simples, pois este é o curso da coisa mesma [grifo nosso]. (HEGEL, 1993a, p. 71) ${ }^{2}$
\end{abstract}

Porém, sabemos que, assim como não há "a" filosofia, mas filosofias, há tantas ciências especiais quanto há filosofias diferentes, e, consequentemente, não podemos afirmar que há um método absoluto de toda filosofia, mas tantos métodos quantos filosofias houver. Porém, isso não impede que cada pensador tenha feito a sua proposta metódica, almejando dar a filosofia um método infalível e consistente. Por isso, se pode dizer que cada filosofia sempre desenvolve implícita ou explicitamente seu discurso do método. Isso assegura que a filosofia sempre é pensada a partir de um determinado modo. E em Hegel, esse modo é mais do que um simples procedimento artificial ou externo ao filosofar, sua dialética de forma alguma pode ser considerada como um "método" no sentido das ciências particulares, ainda que ela pretenda exprimir o que constitui o procedimento científico da reflexão filosófica (cf. OLIVEIRA, 2002, p. 7) ${ }^{3}$, pois, como bem afirma Lima Vaz,

Se o termo método é entendido no sentido moderno, cartesiano e póscartesiano, de um conjunto de regras ou conselhos para bem dirigir a razão das ciências, a expressão método dialético é inadequada e mesmo incorreta [...] a dialética em sua acepção original não é um conjunto de regras ou esquemas de pensamento a ser aplicado indiferentemente a qualquer conteúdo. (LIMA VAZ, 2002, p. 9)

\footnotetext{
${ }^{2}$ Usaremos as letras "a" e "b" para identificar os volumes I e II da tradução espanhola de Mondolfo da Ciência da Lógica: 1993a - Volume I; 1993b - Volume II.

${ }^{3}$ Sobre isso Heidegger é incisivo: "Hegel designa "dialética especulativa" também simplesmente como "o método". Com esta expressão ele não se refere a um instrumento da representação, nem apenas a uma particular maneira de a filosofia proceder. "O método" é o mais intimo movimento da subjetividade, "a alma do ser", o processo de produção através do qual a tessitura da totalidade da realidade do absoluto é efetivada. O método, quer dizer, a dialética especulativa, é para Hegel o rasgo essencial de toda realidade." (HEIDEGGER, 1973, p. 405)
}

\begin{tabular}{|l|l|l|l|l|} 
Revista Dialectus & Ano 1 & n. 2 & Janeiro-Junho 2013 & p. 8-20 \\
\hline
\end{tabular}


Por isso, Hegel busca romper com a "aplicação" de métodos em filosofia, propondo um novo paradigma de investigação, missão já explicitada na Fenomenologia do Espírito:

\begin{abstract}
Mas não é difícil perceber que essa maneira [de proceder] - expor uma proposição, defendê-la com argumentos, refutar o seu oposto com razões - não é a forma como a verdade pode manifestar-se. A verdade é seu próprio movimento dentro de si mesma; mas aquele método é o conhecer que é exterior à matéria. Por isso, como já notamos, é próprio da matemática e deve-se-lhe deixar, pois tem como princípio a relação de grandeza - relação carente-deconceito -, e tem como matéria o espaço morto e o Uno igualmente morto. (HEGEL, 2001, p. 47)
\end{abstract}

Logo, cabe saber as razões do filósofo ao afirmar ser a dialética a lógica do todo, e tê-la como o que vivifica esse "esqueleto morto da lógica", a ponto de se constituir tão somente por meio desse método uma ciência pura. Para Hegel, a dialética não envolve um diálogo entre dois pensadores ou entre um pensador e seu objeto de estudo, pois a dialética não assumirá para o filósofo aquela definição de "arte do diálogo", que busca demonstrar uma tese mediante uma argumentação capaz de definir e distinguir com clareza os conceitos envolvidos na discussão. A dialética em Hegel não é, de forma nenhuma, diferente de seu objeto e conteúdo, pois ela é o conteúdo em si próprio. Ela é a estrutura e o desenvolvimento intrínsecos ao próprio ser.

Primando assim pela compreensão adequada de seu método filosófico, almejamos obter sua estrutura basilar para entender como a dialética justifica o próprio começo da ciência filosófica. E, sendo o método o modo de conhecer, ou a forma de instaurar o ato de conhecer, nos questionamos sobre o "que é dialética?", pois tal pergunta pode muito bem ser reduzida, segundo a perspectiva de Hegel, à própria apreensão do que é a filosofia mesma. $^{5}$

\footnotetext{
${ }^{4}$ Questão homônima a de um artigo de Popper sobre a questão dialética, no qual crítica asperamente o método dialético hegeliano, denunciando o aspecto ininteligível desse método assumido por Hegel e os dialéticos dogmáticos, o que não faremos em nosso trabalho, porém, acreditamos ser enriquecedor expor em nota uma vertente de crítica. Para Popper é problemática a utilização da contradição na busca de uma realidade. Pois tanto Hegel quanto os demais dialéticos afirmam que a contradição é importante na história da filosofia enquanto crítica. Consideram, e isso é lícito segundo Popper, que, sem a contradição e a crítica, não existiria motivo para modificarmos as nossas teorias e nem haveria progresso intelectual. O problema é que há, ali, uma defesa errônea de que não se deve evitar tais contradições, pois elas estão em toda parte. Também porque a sua manutenção é natural e faz parte do processo. Dessa afirmação, os dialéticos concluem a existência de uma nova lógica dialética que se apresenta como uma teoria da evolução histórica do pensamento e uma teoria geral do universo, com a função de substituir a estéril lógica formal (cf. POPPER, 1994; FABIAN, 2006, p. 157-174). Porém, existem aqueles que não consideram Hegel suscetível de tal crítica, já que deixa claro em seu sistema que a contradição não pode ser, não pode subsistir, e deve ser superada, porém reconhece que não se pode negar-lhe a existência, pois é inerente as próprias coisas, pois ela é enquanto transição, ou seja, no próprio devir imediato (cf. UTZ, 2005, p. 177).

${ }^{5}$ Segundo Gadamer: "toda filosofia é, portanto, dialética. Porque todo enunciado, inclusive aquele que enuncie a estrutura interior da coisa, a mútua relação das ideias, contém a contradição do uno e do
} 
Há contradição em todas as coisas, pois “a contradição é a raiz de todo movimento e vitalidade; pois só na medida em que tem algo em si mesmo uma contradição se move, tem impulso [Trieb] e atividade" (HEGEL, 1993b, p. 72). ${ }^{6}$ Assim a metafísica que apresenta a verdadeira natureza das coisas é a metafísica da contradição; e a lógica, que se identifica com tal metafísica, apresenta as próprias determinações imanentes ao pensamento, sendo por isso denominada a lógica da contradição. Hegel põe no lugar da tradicional lógica de raiz aristotélica, na qual se tomaria da metafísica o princípio de nãocontradição e se faria dele o princípio fundamental ao qual toda transição lógica seria requerida a aderir, uma nova lógica, direcionada precisamente ao pensamento da contradição, uma lógica que afirmaria tal pensamento, uma lógica que reconhece plenamente que "é ridículo dizer que a contradição não pode ser pensada". (SALLIS, 2004, p. 48)

Como vemos, essa ciência da lógica é completamente diversa daquela dita tradicional em sua relação com a contradição. Em lugar de um princípio que excluiria a contradição do ser, que a baniria da verdadeira natureza das coisas, a metafísica iria agora, com Hegel, expor a contradição existente por toda parte, em todas as coisas, pois inerente a sua natureza das mesmas. Dessa forma, em vez de excluir a contradição da verdade das coisas, a metafísica, ou melhor, a lógica, libertaria a contradição em todas as coisas, mas tal libertação da contradição não é algo que iria acontecer de maneira externa, como se a contradição fosse levada às coisas, mas ela está ou é nas coisas mesmas, lhes constituindo a própria estrutura interna. É a metafísica da contradição, no sentido de que a contradição se tornaria a própria tarefa à qual a metafísica estaria propensa a evidenciar em todas as coisas - no intuito, é claro, de buscar-lhe resolver e superar.

Por isso, Hegel se refere à contradição como uma "identidade de opostos", pois reconhece que a contradição perdura em todas as coisas, não simplesmente como contradição, mas como um relacionar intrínseco entre os opostos. Note-se que isso já foi antevisto na Fenomenologia do Espírito, onde o espírito não só postula e suporta a contradição, mas também a supera ${ }^{7}$, como bem foi exposto por Gadamer,

múltiplo, de modo que é possível especular esta contradição com uma intenção erística." (GADAMER, 2000, p. 37-38).

${ }^{6}$ O que é mais explícito em um adendo da Enciclopédia, onde se lê: "é a contradição que move o mundo". (HEGEL, 1995, p. 236).

${ }^{7}$ Lê-se no prefácio a Fenomenologia do Espírito: “A morte - se assim quisermos chamar essa inefetividade - é a coisa mais terrível; e suster o que está morto requer a força máxima. A beleza sem- força detesta o entendimento porque lhe cobra o que não tem condições de cumprir. Porém não é a vida

\begin{tabular}{|l|l|l|l|l|} 
Revista Dialectus & Ano 1 & n. 2 & Janeiro-Junho 2013 & p. 8-20 \\
\hline
\end{tabular}


Como pertence à essência do espírito sustentar a contradição e mantê-la nele precisamente como a unidade especulativa dos opostos, a contradição, que era prova de nulidade para os antigos, se converte em algo positivo para a filosofia moderna. (GADAMER, 2000, p. 25)

E principalmente para a filosofia hegeliana. Porém, como pensamento especulativo, a metafísica expõe as contradições, mas não as deixa ficar simplesmente como contradições, como opostos rígidos, é sua tarefa superar a contradição, pois somente nesse trabalho do negativo ocorre o desenvolver do conceito. Esse é o caráter específico do pensamento especulativo: consistir unicamente em agarrar os momentos opostos em sua unidade. ${ }^{8}$ Dessa forma, o pensar especulativo não impõe de fora a unidade sob a qual os momentos contraditórios seriam absolvidos, suprassumidos. Pois cada lado da antinomia, cada momento do processo descobre sua relação intrínseca com seu oposto, tanto que a identidade mesma do momento já prova ser uma identidade de opostos, sendo sua unidade uma fusão de dois momentos, de si mesmo e seu oposto. O que o pensamento especulativo mostra é que na relação com seu oposto cada momento é unido a si mesmo, que ambos os momentos, em sua oposição, são, não obstante, para ser tomados juntos, apreendidos pela razão em sua unidade. Desse modo o pensamento especulativo deixa a positividade da união ser produzida pela negatividade da oposição. Ele agarra a negatividade como determinada e assim a torna ser (cf. HEGEL, 1993a, p. 74).

Por isso, não se pode separar a contradição da própria constituição da realidade, pois isso representaria a negação do devir, ou seja, a incapacidade de perceber que cada conceito encerra em si uma potencialidade que permite sua transformação, em detrimento do processo de determinação o que ocorreria é a estagnação conservadora, peculiar às formas lineares de pensamento. Pois, para ser capaz de captar a contradição intrínseca à realidade, a lógica hegeliana opera por meio de outro tipo de negação, a negação determinada, que faz a transição de um momento dialético a outro, ligando todas as fases entre si e estabelecendo uma continuidade entre elas. A negação

\footnotetext{
que se atemoriza ante a morte e se conserva intacta da devastação, mas é a vida que suporta a morte e nela se conserva, que é a vida do espírito. O espírito só alcança sua verdade à medida que se encontra a si mesmo no dilaceramento absoluto. Ele não é essa potência como o positivo que se afasta do negativo - como ao dizer de alguma coisa que é nula ou falsa, liquidamos com ela e passamos a outro assunto. Ao contrário, o espírito só é essa potência enquanto encara diretamente o negativo e se demora junto dele. Esse demorarse é o poder mágico que converte o negativo em ser." (HEGEL, 2001, p. 38).

${ }^{8}$ Hegel explica precisamente como esta unidade é obtida, como cada um dos opostos se supera precisamente através de si mesmo, por seu próprio desdobramento: "Cada um dos dois lados contém em si mesmo seu outro e nenhum pode ser pensado sem o outro, disso se segue que nenhuma dessas determinações, tomada por si só, tem verdade, senão que a tem apenas [em] sua unidade. Esta é a verdadeira consideração dialética delas, tal como seu verdadeiro resultado." (HEGEL, 1993a, p. 255).
}

\begin{tabular}{|l|l|l|l|l|} 
Revista Dialectus & Ano 1 & n. 2 & Janeiro-Junho 2013 & p. 8-20 \\
\hline
\end{tabular}


determinada expressa o movimento em direção a solução daquela inconsistência ou falta que o primeiro momento do processo dialético sofre, o que possibilita o processo de determinação, esse automovimento da unidade dialética. Isto é, a própria negação será negada de modo determinado, ou seja, vai ser negada de maneira, que ela mesma permaneça conservada em seu negativo. Processo descrito no esquema: afirmação negação - negação da negação ou negação determinada, que dita o ritmo da dialética hegeliana. Por isso, para Hegel, o pensamento especulativo é o único que, por meio da negação determinada, pode abranger a contradição ${ }^{9}$, o que pode ser atribuído a essa característica toda especial da dialética hegeliana. ${ }^{10}$

Para Hegel, a contradição entre os dois primeiros termos é intrínseca ao conteúdo deles e tem de ser preservada, transformada, levada adiante, o que significa ser suprassumida, para que se dê a transição de um momento a outro. Assim o método dialético hegeliano é o processo no qual a contradição deve ser considerada e trabalhada, pois, como ele mesmo diz no primeiro volume da Enciclopédia das Ciências Filosóficas em Compêndio (cf. HEGEL, 1995, p. 163), ela ocorre e deve ser tida como a própria alma motriz do pensamento e da própria ciência. Hegel põe a contradição no próprio núcleo do pensamento e das coisas, simultaneamente. ${ }^{11} \mathrm{O}$ pensamento não é mais estático, ele procede por meio de contradições superadas e guardadas, como num diálogo em que a verdade surge a partir da discussão e das contradições. Uma proposição não pode se pôr sem se opor a outra em que a primeira é negada, transformada em outra que não ela mesma. Essas proposições se solicitam umas as

\footnotetext{
${ }^{9}$ O que Hegel já expôs na introdução: "é o reconhecimento da proposição lógica, que afirma que o negativo é por sua vez positivo, ou que o contraditório não se resolve em um zero, em um nada abstrato, senão só essencialmente na negação de seu conteúdo particular; quer dizer, que tal negação, não é qualquer negação, senão a negação daquela coisa determinada, que se resolve, e por isso é uma negação determinada." (HEGEL, 1993a, p. 71).

${ }^{10} \mathrm{O}$ que é apresentado por Koyré: "Quando Hegel nos fala de oposição e de contradição, ele não pensa numa relação entre os dois termos. Ele pensa, ou melhor, ele vê em si mesmo um ato que "apresenta" alguma coisa e um outro que lhe "opõe" outra coisa, que "se opõe" à ação do primeiro; um ato que "diz" alguma coisa, alguma coisa que é "contra-dita" [...] Poderíamos dizer que contrariamente à tradição milenar da filosofia, Hegel não pensa com substantivos mas com verbos." (KOYRÉ, 1991, p. 129-130).

${ }^{11}$ Ainda que reconheça que há grande mérito em Fichte e Schelling, no assumir dessa busca dialética de valoração positiva da contradição, da negação, Hegel denuncia o fracasso de ambos por não conceberem o não em seu verdadeiro lugar: no próprio absoluto positivo. Isso foi registrado por Koyré: "De fato, o Absoluto de Fichte suprime o não; o Absoluto de Schelling o ignora. E por isso mesmo os dois permanecem $a b$-solus, separados, transcendentes ao ser, à razão. Permanecem imóveis e inconscientes. E Hegel imagina que é preciso ir adiante, mais alto. Colocar o não no sim; mostrar o múltiplo no uno, mostrar no próprio infinito, o finito; no eterno, tempo, o movimento, a inquietude que para ele é a própria essência do real." (KOYRÉ, 1991, p. 123). Pois como bem diz Garaudy: "O sistema hegeliano não é a conclusão de uma espécie de silogismo histórico ao termo do qual o idealismo absoluto de Hegel sucederia por uma necessidade lógica ao idealismo subjetivo de Fichte e ao idealismo objetivo de Schelling." (GARAUDY, 1970, p. 3).
} 
outras, e, apesar de opostas, tendem a formar uma "unidade de contrários", uma grande síntese (cf. CIRNE-LIMA, 2003, p. 16). Tal relação é a dialética, na qual, por sua interdependência, nenhuma dessas proposições pode existir sem estar em diálogo com as demais. Assim, a primeira proposição encontrar-se-á finalmente transformada e enriquecida numa nova fórmula que era, entre as duas precedentes, uma ligação, uma mediação, uma reflexão (cf. NICOLAU, 2007, p. 130).

Seria esse o verdadeiro método da filosofia, que não apenas se distinguiria dos métodos analítico e sintético, pois conteria também os elementos positivos desses, enquanto suprassumidos:

O método da verdade, que concebe o objeto, é sem dúvida, como já foi demonstrado, analítico ele mesmo, pois permanece absolutamente no conceito; porém é ao mesmo tempo sintético, pois por meio do conceito, o objeto está determinado dialeticamente e como outro. (HEGEL, 1993b, p. 576)

Tal método dialético visa preservar a ciência filosófica de cair no unilateralismo do entendimento, que separa os diferentes e não vê relação entre eles. Tal proceder unilateral estabelece uma identidade morta, insuficiente e incompleta, pois a identidade por si só, destacada da diferença, é carente de sentido, e, considerada por si só, acaba por frear o processo de determinação. Hegel sabe que não se pode negar o princípio de nãocontradição ou identidade, pois ninguém pode a ele abandonar sem arriscar a própria racionalidade da argumentação proposta, mas também sabe que ele não pode fixar uma oposição insolúvel entre identidade e diferença, pois a identidade só é concreta em si quando se encontra posta em relação à outra determinação lógica, a diferença. ${ }^{12}$

Com sua lógica especulativa, Hegel mostra a nulidade de uma identidade formal, que abstrai a diferença de si, mas que também não pode, inversamente, ficar na simples diversidade, pois deve reconhecer uma unidade interior em tudo o que existe. Deve ser reconhecida uma unidade na coisa, uma determinação que a faz ser o que é. Para tanto, apresenta que a diferença essencial, posta sob a forma de uma positividade e uma negatividade, tem cada um desses elementos como uma determinação, na medida em

\footnotetext{
${ }^{12}$ Para Hegel, na Doutrina da Essência, tal princípio tido dessa forma não passa de uma lei do entendimento abstrato: "Este princípio, em sua expressão positiva: $\mathrm{A}=\mathrm{A}$, não é, em primeiro lugar, mais que a expressão de uma tautologia vazia. Portanto tem-se observado corretamente que esta lei do pensamento não tem conteúdo e não leva adiante [...] Se concede que o princípio de identidade expressa apenas uma determinação unilateral, e contém apenas a verdade formal, quer dizer, uma verdade abstrata, incompleta. - Porém neste juízo correto, está subentendido imediatamente que a verdade está completa apenas na unidade da identidade com a diferença, e, por conseguinte, consiste apenas nessa unidade." (HEGEL, 1993b, p. 38).
} 
que um não é o outro. Porém, cada um desses aparece no outro, ou seja, seu determinar mantém relação com a determinação que é o outro, sendo somente na medida em que o outro é, pois:

não se pode formular uma proposição sem que entrem já em jogo as categorias da identidade e da diferença [...] todo aquele que formule proposições utiliza palavras distintas e entende por cada palavra isto e não aquilo, com o qual ambas as categorias, identidade e diferença, estão aí implicadas. (GADAMER, 2000, p. 85-86)

Da mesma forma que a identidade em si é um princípio vazio, o é a diferença em si, essa "é a carência-de-pensamento, peculiar da abstração: por lado a lado, como leis, essas duas proposições contraditórias, sem sequer compará-las.” (HEGEL, 1995, p. 234). A contradição nunca pode ser algo provindo de uma ação subjetiva, logo não pode deixar de ser considerada, pois é um pensar da necessidade, essencial a tudo. Assim tudo se determina através de uma relação recíproca, onde um outro se relaciona com seu outro e se torna o outro do outro, assim ocorre na identidade com a diferença, e em um nível mais elevado, no positivo com o negativo. Por isso, ratifica Hegel: “o fim da filosofia é banir a indiferença e reconhecer a necessidade das coisas, de sorte que o Outro apareça como defrontando o seu Outro.” (HEGEL, 1995, p. 236). Não pode existir, como quer o entendimento, um tão abstrato "ou-ou”, pois tudo é um concreto, tudo é um algo em si mesmo oposto e diferente.

O método, identificado aqui à interioridade que se move, é relação de si a si. O método hegeliano extrai sua determinação do relacionar intrínseco ao conteúdo. Este é o ponto crucial da filosofia de Hegel, onde "atua" em verdade seu futuro idealismo monista ${ }^{13}$ ou absoluto, sendo considerado como filosofia que atingiu um reconhecimento da realidade dual enquanto que fundamentalmente relacional.

Assim o método de Hegel não determina as etapas que levam à construção do sistema, ele exprime o próprio sistema, não é o método da filosofia especulativa, mas a

\footnotetext{
${ }^{13}$ Basicamente se usa o termo monismo para se referir aos filósofos que só admitem uma substância, mas, segundo informação de Mora, durante um tempo foi comum chamar "monistas" aos que seguiam as doutrinas de Hegel, pois podiam ser considerados assim todos aqueles que identificassem a realidade com algum Absoluto que se manifesta, seja como sujeito e objeto, seja como matéria e espírito. Nessa perspectiva as relações têm que ser internas à realidade considerada, ou seja, constituir esta realidade como tal. Deste modo nenhuma "realidade" é independente, senão que está relacionada ou integrada com o Todo. Qualquer enunciado sobre qualquer coisa é impossível (ou parcial) a menos que se refira ao Todo. Daí que neste tipo de monismo somente possa se falar de verdade como um todo, segundo havia proposto Hegel. Como toda proposição, tomada isoladamente, é parcial e falsa, a verdade como tal é unicamente o desenvolver do Todo mesmo sob a forma de uma proposição acerca de si mesmo. (Cf. MONISMO. In: MORA, 1964, p. 227-228).
}

\begin{tabular}{|l|l|l|l|l|} 
Revista Dialectus & Ano 1 & n. 2 & Janeiro-Junho 2013 & p. 8-20 \\
\hline
\end{tabular}


própria filosofia especulativa. ${ }^{14}$ Esse processo, busca de uma grande síntese, Hegel indicou pelo verbo Aufheben e o substantivo die Aufhebung - traduzidos pelo saudoso Pe. Meneses -, respectivamente, por "suprassumir" e "suprassunção". ${ }^{15}$ Em uma nota na Lógica, de suma importância para a compreensão do estilo dialético que Hegel se propõe seguir, temos a explicação do Aufheben, que representa o próprio desenvolvimento conceitual da Lógica, que no avançar do processo supera e conserva cada momento desenvolvido.

É interessante encontrarmos no prefácio à Fenomenologia do Espírito o parecer de Hegel sobre o modelo triádico (Cf. HEGEL, 2001, p. 48), provindo de Kant e assumido por Fichte, que muitos autores de Histórias da Filosofia têm como próprio de Hegel ${ }^{16}$, mas que ele mesmo não emprega em nenhum lugar essa terminologia para designar sua própria dialética, logo, a forma tese-antítese-síntese não deve ser vista sem reservas impostas pelo próprio Hegel. Para ele, tal forma triádica é ainda carente-de- conceito e morta, um esquema sem vida, um verdadeiro fantasma, igualando-se ao formalismo já tão criticado anteriormente, pois o método científico não pode ser reduzido a uma mera "tabela". Assim, a estrutura do processo dialético hegeliano, dita por muitos manuais "triádica", poderia ser tida, com aval do próprio Hegel, como constituída por quatro fases. ${ }^{17} \mathrm{O}$ que é exposto por Hegel na passagem:

$\underline{S e}$ (grifo nosso) em geral se quiser contar [ ] o termo que é contado como terceiro pode também ser contado como quarto, e a forma abstrata pode considerar-se, em lugar de uma forma tripla, como uma forma quádrupla. $\mathrm{O}$ negativo, ou seja, a diferença, se encontra desse modo contado como uma duplicidade. - O terceiro, ou seja, o quarto, é em geral a unidade do primeiro e do segundo momento, do imediato e do mediado. - Que seja esta unidade,

\footnotetext{
${ }^{14}$ Como bem é expresso nas palavras de Garaudy: “A dialética não é, por conseguinte, somente a reprodução, no pensamento, do ritmo de desdobramento da totalidade orgânica, ela é este desenvolvimento mesmo. Não é a reprodução; é a produção.” (GARAUDY, 1970, p. 181).

15 Assim o eminente tradutor se justifica na Enciclopédia: "usamos suprassumir para Aufheben [...] O prefixo 'supra' não nos pareceu despropósito, já que toda gente diz supracitado, supra-sensível, etc. Suprassumir é melhor que 'sobressumir', não porque 'sobre' tem ressonância de 'em cima', e supra a de 'acima', mas porque a ambiguidade sumir/suprassumir fica muito bem para este 'desaparecer conservante' que é o Aufheben." (HEGEL, 1995, p. 9-10). O que já é consequência da proposta de Gauthier, assumida pelos tradutores franceses da Lógica: "Propomos a tradução 'suprassumir', 'suprassunção' para Aufheben e Aufhebung. A derivação etimológica apóia-se no modelo assumir, assunção. A semântica da palavra corresponde ao antônimo de 'subsunção' que se encontra em Kant. A suprassunção define portanto uma operação contrária àquela da subsunção, que consiste em colocar a parte dentro da totalidade ou sob ela; a suprassunção, a Aufhebung, designa o processo de totalização da parte.” (GAUTHIER, 1967, p. 15).

${ }^{16}$ A atribuição desse modelo à filosofia de Hegel é obra, sobretudo, de um de seus discípulos, Karl Lwdwig Michelet (1801-1893).

${ }^{17}$ Porém, não é o número de fases que importa, mas a continuidade que marca a essência dessa dialética, como bem expõe Labarriére: "É ilusão, por conseguinte, querer apreender o movimento dialético a partir desta impossível fixação dos momentos que ele percorre; ele não é nem um, nem dois, nem três, nem quatro, e ele é tudo isto ao mesmo tempo: só resta a maleabilidade de um esquema apto a tomar a forma da transitividade essencial do real." (LABARRIÈRE, 1986, p. 96).
} 
como também que toda a forma do método seja uma triplicidade, é por certo apenas o lado superficial, extrínseco da maneira de conhecer. (HEGEL, 1993b, p. 574)

Pois podemos reconhecer como momentos do processo um primeiro (em-si, imediato, universal), um segundo (ser-aí, particular e primeiro negativo), um terceiro (serpara-si, negação absoluta ou negação da negação), e, por fim, um quarto (ser-em-si- parasi, um singular) (cf. TIMMERMANS, 2005, p. 44-45). Isso se dá porque o processo dialético supera a contradição posta por ele mesmo, pois não se pode permanecer na contradição, se devendo buscar sua solução. Note-se que a contradição é o que não pode ser, ela não pode subsistir no sentido de se fixar, permanecer, sob o risco do discurso perder sua logicidade. Esses dois tipos de negatividade, bem diferentes um do outro, que se sucedem, podem ser determinados da seguinte forma: a primeira desempenha o papel de uma relação com um outro, um deparar-se frente a um outro, gerando uma particularização, a segunda negação, diversamente, trabalha no sentido de uma afirmação de si, e já constitui um novo ciclo posto de uma nova contradição, e é aqui que podemos afirmar um terceiro momento que já pode ser identificado como um quarto. Esse dito quarto momento dialético é na verdade a unidade dos três momentos aludidos, ele é a verdadeira grande síntese.

\footnotetext{
A negatividade considerada constitui agora o ponto de ligação do movimento do conceito. É o ponto simples da referência negativa a si mesmo, a fonte mais íntima de toda atividade, de todo automovimento vivente e espiritual, a alma dialética, que tem todo verdadeiro em si mesmo, e por cujo meio ela somente é um verdadeiro: com efeito, somente sobre esta subjetividade se funda a eliminação da oposição entre conceito e realidade e unidade, que é a verdade. (HEGEL, 1993b, p. 573)
}

Segundo Hegel, o processo de determinação do conceito, a ciência filosófica, é compreendido através da transição daquele momento inicial, um simples imediato, que se reconhece como um mediado relacionado com um outro, ou seja, que o universal, mesmo em sua imediaticidade, é um particular. Logo, esse outro, esse segundo que surgiu, é o negativo do primeiro, e deve ser considerado como o primeiro negativo, o qual já conceituamos acima. Esse momento de relação com um outro acaba por marcar o perecer desse primeiro, do imediato; mas esse outro, momento de uma primeira negação, não pode ser considerado um negativo vazio, um simples nada que marcaria a impossibilidade da progressão proposta por Hegel, como se nós fossemos levados a cair em uma aporia insolúvel, mas, na verdade, esse outro do primeiro, ou negativo do imediato, está determinado como o mediado porque contém em si a determinação do primeiro, logo também pode ser atribuído a ele um caráter positivo e determinado.

\begin{tabular}{|l|l|l|l|l|}
\hline Revista Dialectus & Ano 1 & n. 2 & Janeiro-Junho 2013 & p. 8-20 \\
\hline
\end{tabular}


Ocorre aqui a Aufhebung, pois o primeiro é conservado e mantido no outro, ainda que esse outro seja sua negação. Assim, a dialética hegeliana busca a todo custo manter firme esse positivo em seu negativo, sob o risco de parar o processo de determinação caso isso não fosse realizado. Para Hegel,

se precisa ao mesmo tempo apenas a mais simples reflexão para convencer-se da absoluta verdade e necessidade desta exigência, e pelo que se refere aos exemplos a propósito de provas, toda a lógica consiste nisto. (HEGEL, 1993b, p. 571)

Salienta-se, então, que o segundo negativo, o negativo do negativo, consiste naquela superação da contradição, dita anteriormente como extremamente necessária, sendo ela "o momento mais íntimo, mais objetivo da vida e do espírito, por cujo meio este chega a ser um sujeito, uma pessoa, um livre." (HEGEL, 1993b, p. 573)

A dialética hegeliana engloba o momento do especulativo ou positivamente racional (cf. HEGEL, 1995, p. 166-167), ou seja, o jogo das determinações que se eliminam e complementam reciprocamente, movimento de produção de conceitos que é identificado com o próprio conceito (Begriff). O desenvolvimento do conceito anuncia claramente a verdade da dialética. Por isso, a dialética é tida por Hegel como procedimento superior do pensamento, e, ao mesmo tempo, a marcha e o ritmo das próprias coisas:

\footnotetext{
Chamamos dialética ao superior movimento racional, no qual tais termos, que aparecem absolutamente separados, transitam um ao outro por si mesmos, por meio do que eles são; e, assim, a pressuposição [de seu estar separados] se suprassume. (HEGEL, 1993a, p. 136)
}

E a natureza do princípio da filosofia se impõe para Hegel justamente por ser ele consciente de que não se pode aderir a nenhum método que seja exterior a seu conteúdo, se deve antes buscar um método capaz de unir forma e conteúdo, método esse que tem raiz dialética, e está inteiramente unido ao próprio desenvolver do conceito, ou seja, da Ideia Absoluta.

\section{Referências Bibliográficas}

HEGEL, G. W. F. Ciencia de la Logica. 2 vol. $6^{\text {a }}$ ed. Tradução de Augusta e Rodolfo Modolfo. Buenos Aires: Librarie Hachette, 1993. Montaigne, 1976.

Science de la logique - La doctrine de l'essence. Paris: Aubier

\begin{tabular}{|l|l|l|l|l|} 
Revista Dialectus & Ano 1 & n. 2 & Janeiro-Junho 2013 & p. 8-20 \\
\hline
\end{tabular}


Enciclopédia das Ciências Filosóficas - a Ciência da Lógica. Tradução Paulo Menezes, com a colaboração de José Machado. São Paulo: Edições Loyola, 1995.

. Fenomenologia do Espírito - Parte I. 2 vol. Tradução de Paulo Menezes com colaboração de Karl-Heinz Efken. 6ª ed. Petrópolis: Vozes, 2001.

BRITO, E. F. de.; CHANG, L. H. (Org.). Filosofia e método. São Paulo: Edições Loyola, 2002.

CHAGAS, E. F.; UTZ, K.; OLIVEIRA, J. W. J. (Org.). Comemoração aos 200 anos da "Fenomenologia do Espírito" de Hegel. Fortaleza: Edições UFC, 2007.

CIRNE-LIMA, C. R. V. Dialética para principiantes. $3^{\text {a }}$ ed. São Leopoldo: Editora Unisinos, 2003. (Coleção Idéias, v. 5)

; ALMEIDA, C. (orgs.). Nós e o absoluto. Fortaleza/São

Paulo: Edições UFC/ Edições Loyola, 2001.

FABIAN, E. P. A relação entre método e política em Hegel a partir de "A Sociedade Aberta e seus Inimigos" de Karl Popper. In: Revista de Ciências Humanas, Frederico Westphalen, v. 7, n. 8, Jun. 2006, p. 157-174.

GADAMER, H.-G. La dialéctica Hegel - Cinco ensayos hermenéuticos. $5^{\mathrm{a}}$ ed. Tradução de Manuel Garrido. Madrid: Ediciones Cátedra, 2000.

GARAUDY, R. Dieu est mort - Étude sur Hegel. Paris : Presses Universitaires de France, 1970.

GAUTHIER, Y. Logique hégélienne et formalisation. In: Dialogue - Revue Cannadienne de Philosophie, Toronto, set. 1967, p. 15, nota 5; apud JARCZIK, G.; LABARRIERE, P. J. "Présentation »à G.W.F. Hegel. In: HEGEL, G. W. F. Science de la logique - La doctrine de l'essence. Paris: Aubier Montaigne, 1976, pág. XXVIII.

HEIDEGGER, M. Hegel e os gregos. Tradução de Ernildo Stein. In: Sartre - Heidegger. São Paulo: Abril Cultural, 1973 (Coleção os Pensadores, vol. XLV).

JARCZIK, G; LABARRIÈRE, J. P. Hegeliana. Paris: PUF, 1986.

KOYRÉ, A. Estudos de história do pensamento filosófico. Tradução de Maria de Lourdes Menezes. Rio de Janeiro: Forense Universitária, 1991.

LIMA VAZ, H. C. Método e dialética. In: BRITO, E. F. de.; CHANG, L. H. (Org.). Filosofia e método. São Paulo: Edições Loyola, 2002, p. 9-17.

MORA, J. F. Diccionário de filosofia - Tomo II. Buenos Aires: Editorial Sudamericana, 1964.

NICOLAU, M. F. A. O movimento dialético na introdução ao sistema da ciência - O prefácio a Fenomenologia do Espírito. In: CHAGAS, E. F.; UTZ, K.; OLIVEIRA, J. 
W. J. (Org.). Comemoração aos 200 anos da "Fenomenologia do Espírito" de Hegel. Fortaleza: Edições UFC, 2007, 127-144.

OLIVEIRA, M. A. de. Para além da fragmentação - Pressupostos e objeções da racionalidade dialética contemporânea. São Paulo: Edições Loyola, 2002.

POPPER, K. O que é dialética? In: . O racionalismo crítico na política coletânea de Ensaios. Brasília: UnB, 1994.

SALLIS, J. Lógica Exorbitante: no limite da Metafísica da Contradição. In: Revista Tempo da Ciência, Toledo, v. 11, n. 22, $2^{\circ}$ sem. 2004, p. 39-56

STEIN, E. A questão do método na filosofia: um estudo do modelo heideggeriano. Porto Alegre: Movimento, 1983. p. 13, apud. ROHDEN, L. Verdade contra o método? - Sobre o método filosófico em Montaigne, Descartes e Gadamer. In: CIRNE-LIMA, C.; ALMEIDA, C. (orgs.). Nós e o absoluto. Fortaleza/São Paulo: Edições UFC/ Edições Loyola, 2001.

TIMMERMANS, B. Hegel. Tradução de Tessa Moura Lacerda. São Paulo: Estação Liberdade, 2005 (Coleção Figuras do Saber; v.12).

UTZ, K. O método dialético de Hegel. In: Revista Veritas, Porto Alegre, v. 50, n. 1, Mar. 2005, p. 165-185. 